\title{
Role of Agri-Input Dealers in Transfer of Technology
}

\author{
U. Kiran Kumar Reddy*, P.V. Satya Gopal, V. Sailaja and S.V. Prasad \\ Department of Agricultural Extension, S.V. Agricultural College, Tirupati 517502, \\ Andhra Pradesh, India \\ *Corresponding author
}

Keywords

Manifest role, Agriinput dealers

Article Info

Accepted:

18 January 2019

Available Online:

10 February 2019

\section{A B S T R A C T}

The research study was conducted to study the role of the agri-input dealers in transfer of technology in Southern Telangana zone of Telangana state. The study revealed that more than half $(55.83 \%)$ of the agri-input dealers have perceived medium role, followed by high role $(23.34 \%)$ and low role $(20.83 \%)$ in transfer of technology. When comes to manifest role more than half $(55.83 \%)$ of the agri-input dealers had 501 to 1000 farmers as customers, 30 to 60 farmers visiting the shop per day for more than half $(53.33 \%)$ of the agri-input dealers, more than half $(58.34 \%)$ of the agri-input dealers have made 6 to 10 field visits to farmer fields per month, more than two fifth $(41.57 \%)$ of the farmers were orally expressing the problem to the agri-input dealers, nearly half of the $(46.28 \%)$ technical assistance is provided by the agri-input dealers on pesticides, more than two fifth $(42.12 \%)$ of pesticides were sold by the agri-input dealers in their shops, nearly half $(49.35 \%)$ of farmers purchase inputs by direct contact of agri-input dealer.

\section{Introduction}

Today, India ranks second worldwide in farm output. Agriculture and allied sectors accounted for 17.30 per cent of the GDP (Gross Domestic Product) in 2017, about 53 per cent of the workforce (Economic Survey Report 2017-2018). The economic contribution of agriculture to India's GDP is steadily declining with the country's broadbased economic growth. Still, agriculture is demographically the broadest economic sector and plays a significant role in the overall socio-economic development of India. The sphere of influence of agriculture is unlimited and touches almost all the systems of life with due reputation. Starting from the primary stake holders of agriculture i.e., farmers to the ultimate inventors of the technologies i.e., the scientists, different sorts of people were involved in creation of food for the billions of people with diverse roles and responsibilities.

The two important factors for the development of agriculture are research and extension. Development of new technologies, and their associated inputs, post-harvest processing to the final marketing and prices of all the farm produce are critical in improving 
farm productivity. On the other side, transfer of all such information to the farming community is of paramount important challenge for the stakeholders. Mostly the farmers are not aware of correct types and dosage required for particular agrochemicals for different crops and new technologies. In the changing scenario of agricultural extension it is still becoming more and more complex and projecting the diversified ways and means for transfer of agricultural technology.

An efficient extension system capable of timely dissemination of need based farm technology among farming communities is vital for achieving sustained growth in agriculture. The system of transfer of technology from research to the farmers through appropriate stakeholders played a crucial role in modernizing agriculture.

One among such stake holders are agri-input dealers playing tremendous role in reaching the farmers by performing duel role of providing agri-inputs as well as technological back up to the farmers informally. They are the chief source of farm information to the farming community with utmost credibility. Besides the supply of inputs and credit, their role in transfer of agricultural technology is notable and acclaimed by the farmers for their accessibility and adorability. In spite of not having formal agricultural education, their words are very much appealing to the farmers resulting in development of strong linkage to meet their agri-input demands.

\section{Materials and Methods}

Ex-post-facto research design was used in the present investigation. The Telangana state was chosen as the locale of the study. Southern Telangana zone from Telangana state was selected for the study, since the researcher belongs to the zone and was familiar with local agricultural situations.
Two districts from Southern Telangana zone viz., Jogulamba Gadwal and Suryapet, were selected purposively based on highest number of agri-input dealers. Three mandals from Jogulamba Gadwal district viz., Gadwal, Alampur, Ieeja and three mandals from Suryapet district viz., Suryapet, Kodad, Huzurnagar were purposively selected based on the highest number of agri-input dealers thus makes total of six mandals. From each of the selected mandal, twenty respondents were selected randomly from the list of the agriinput dealers obtained from the officials of the State Department of Agriculture, making a total of 120respondents.

\section{Results and Discussion}

\section{Role assessment of agri-input dealers in transfer of technology}

Agri-input dealers are the potential localite sources of information having high credibility among the farmers. As they are the connecting bridges between researchers, extension functionaries, input agencies and farming community, their role is more significant in meeting the demands of the farmers. It is clearly noticed from table 1 . That, more than half $(55.83 \%)$ of the agriinput dealers have perceived medium role, followed by high role $(23.34 \%)$ and low role $(20.83 \%)$ in transfer of technology. As agriinput dealers are linked with supply \& service of agri-inputs, there is more reliance on agriinput dealers by the farmers. So the farmers will approach them with easy access, high dependence, more credibility, clear intension and less ambiguity. Hence the role of agriinput dealers is very prominent in transfer of technology and their faithful performance is always a yardstick for their growth. This could be the possible reason for the above trend. The findings of the present study were similar with the findings of Sangamesh (2012). 
Manifest role of agri-input dealers in transfer of technology

Different criteria were identified to measure the manifest role of agri-input dealers in transfer of technology. The criteria include

Number of farmers as customers for the agri-input dealers

It is clearly noticed from table 2 . that, more than half $(55.83 \%)$ of the agri-input dealers had 501 to 1000 farmers as customers, followed by 23.34 per cent of agri-input dealers had less than 500 farmer as customers and 20.83 per cent of agri-input dealers had more than 1000 farmer as customers.

\section{Number of farmers visiting the shop/day}

It could be inferred from table 3. that, 30 to 60 farmers visiting the shop per day for more than half $(53.33 \%)$ of the agri-input dealers, followed by 26.67 per cent of agri-input dealers with more than 60 farmers visiting the shop per day and less than 30 farmers visiting the shop per day for 20.00 per cent of the agri-input dealers.

\section{Number of field visits by the agri-input dealers / month}

It could be seen from the table 4. that, more than half $(58.34 \%)$ of the agri-input dealers have made 6 to 10 field visits to farmer fields per month, followed by 25.83 per cent of the agri-input dealers have made less than 5 field visits to farmer fields per month and 15.83 per cent of the agri-input dealers have made more than 10 field visits to farmer fields per month.

\section{Proportion of technical assistance given to the farmers}

It could be inferred from the table 5. that, more than two fifth $(41.57 \%)$ of the farmers were orally expressing the problem to the agri-input dealers followed by 34.20 per cent of the farmers directly asking for the brand, about 12.45 per cent of the farmers bringing the sample for prescription and only 11.78 per cent of the farmers asking for the chemical.

\section{Proportion of technical assistance in terms} of various inputs

It could be inferred from the table 6 . that, nearly half of the (46.28\%) technical assistance is provided by the agri-input dealers on pesticides, followed by 30.60 per cent on fertilizers, 22.19 per cent on seeds and 0.93 per cent on other miscellaneous inputs.

Proportion of various inputs sold in the shop (in monitory terms)

It could be inferred from the table 7. that, more than two fifth $(42.12 \%)$ of pesticides were sold by the agri-input dealers in their shops, followed by 33.95 per cent of fertilizers, 23.29 per cent of seeds and only 0.64 per cent of other miscellaneous inputs were sold in their shops.

Proportion of references for purchase of inputs

It could be elucidated from the table 8 . that, nearly half $(49.35 \%)$ of farmers purchase inputs by direct contact of agri-input dealer, followed by 27.80 per cent of farmers by the reference of progressive farmers, 11.24 per cent of farmers by the reference of agricultural officer, 8.02 per cent of farmers by the reference of company representatives and 3.59 per cent of farmers by the reference of scientists.

A glance at the table 9. Indicated that relationship between independent variables of the agri-input dealers and their role in transfer of technology. 
Table.1 Distribution of agri-input dealers according to their role in transfer of technology

\begin{tabular}{|c|l|c|c|}
\hline S. No. & \multicolumn{1}{|c|}{ Category } & Frequency & Percentage \\
\hline $\mathbf{1}$ & Low role in transfer of technology & 25 & 20.83 \\
\hline $\mathbf{2}$ & Medium role transfer of technology & 67 & 55.83 \\
\hline $\mathbf{3}$ & High role transfer of technology & 28 & 23.34 \\
\hline \multicolumn{2}{|r|}{ Total } & $\mathbf{1 2 0}$ & $\mathbf{1 0 0}$ \\
\hline Mean $=\mathbf{1 3 0 . 5}$ & & $\mathbf{S D}=\mathbf{3 7 . 1 4}$ \\
\hline
\end{tabular}

Table.2 Number of farmers as customers for the agri-input dealers

\begin{tabular}{|c|l|c|c|}
\hline S. No. & \multicolumn{1}{|c|}{ Category } & Frequency & Percentage \\
\hline $\mathbf{1}$ & Less than 500 & 28 & 23.34 \\
\hline $\mathbf{2}$ & 501 to 1000 & 67 & 55.83 \\
\hline $\mathbf{3}$ & More than 1000 & 25 & 20.83 \\
\hline Maximum : 1594 & & Minimum : 316 \\
\hline
\end{tabular}

Table.3 Number of farmers visiting the shop/day

\begin{tabular}{|c|l|c|c|}
\hline S. No. & \multicolumn{1}{|c|}{ Category } & Frequency & Percentage \\
\hline $\mathbf{1}$ & Less than 30 & 24 & 20.00 \\
\hline $\mathbf{2}$ & 30 to 60 & 64 & 53.33 \\
\hline $\mathbf{3}$ & More than 60 & 32 & 26.67 \\
\hline Maximum : 156 & & Minimum : 15 \\
\hline
\end{tabular}

Table.4 Number of field visits by the agri-input dealers/month

\begin{tabular}{|c|c|c|c|}
\hline S. No. & Category & Frequency & Percentage \\
\hline $\mathbf{1}$ & Less than 5 & 31 & 25.83 \\
\hline $\mathbf{2}$ & 5.1 to 10 & 70 & 58.34 \\
\hline $\mathbf{3}$ & More than 10 & 19 & 15.83 \\
\hline Maximum : 21 & & Minimum : 3 \\
\hline
\end{tabular}

Table.5 Proportion of technical assistance given to the farmers

\begin{tabular}{|c|l|c|}
\hline S. No. & \multicolumn{1}{|c|}{ Category } & Percentage \\
\hline $\mathbf{1}$ & Asking for the Chemical & 11.78 \\
\hline $\mathbf{2}$ & Asking for the brand & 34.20 \\
\hline $\mathbf{3}$ & Bringing sample for prescription & 12.45 \\
\hline $\mathbf{4}$ & Oral expression of the problem & 41.57 \\
\hline & & $\mathbf{1 0 0 . 0 0}$ \\
\hline
\end{tabular}


Table.6 Proportion of technical assistance in terms of various inputs

\begin{tabular}{|c|c|c|}
\hline S. No. & Category & Percentage \\
\hline 1 & Fertilizers & 30.60 \\
\hline 2 & Pesticides & 46.28 \\
\hline 3 & Seeds & 22.19 \\
\hline 4 & Other miscellaneous inputs & 0.93 \\
\hline \multicolumn{2}{|r|}{ Total } & 100.00 \\
\hline
\end{tabular}

Table.7 Proportion of various inputs sold in the shop (in monitory terms)

\begin{tabular}{|c|c|c|}
\hline S. No. & Category & Percentage \\
\hline 1 & Fertilizers & 33.95 \\
\hline 2 & Pesticides & 42.12 \\
\hline 3 & Seeds & 23.29 \\
\hline 4 & Other miscellaneous inputs & 0.64 \\
\hline & Total & 100.00 \\
\hline
\end{tabular}

Table.8 Proportion of references for purchase of inputs

\begin{tabular}{|c|c|c|}
\hline S. No. & Category & Percentage \\
\hline 1 & Reference of agricultural officer & 11.24 \\
\hline 2 & Reference of scientist & 3.59 \\
\hline 3 & Reference of company representatives & 8.02 \\
\hline 4 & Reference of progressive farmers & 27.80 \\
\hline 5 & Direct contact of input dealers & 49.35 \\
\hline & Total & 100.00 \\
\hline
\end{tabular}

Table.9 Correlation coefficients between selected profile characteristics of agri-input dealers and their role in transfer of technology

\begin{tabular}{|l|l|c|}
\hline S. No. & \multicolumn{1}{|c|}{ Independent variables } & 'r' values \\
\hline $\mathbf{1}$ & Age & $0.096^{\mathrm{NS}}$ \\
\hline $\mathbf{2}$ & Education & $0.186^{*}$ \\
\hline $\mathbf{3}$ & Experience as a agri-input dealers & $0.026^{\mathrm{NS}}$ \\
\hline $\mathbf{4}$ & Farming experience & $-0.107^{\mathrm{NS}}$ \\
\hline $\mathbf{5}$ & Land holding & $-0.038^{\mathrm{NS}}$ \\
\hline $\mathbf{6}$ & Training received & $0.619^{* *}$ \\
\hline $\mathbf{7}$ & Mass media usage & $0.019^{\mathrm{NS}}$ \\
\hline $\mathbf{8}$ & Social participation & $0.046^{\mathrm{NS}}$ \\
\hline $\mathbf{9}$ & Extension contact & $0.683^{* *}$ \\
\hline $\mathbf{1 0}$ & Scientific orientation & $0.428^{* *}$ \\
\hline $\mathbf{1 1}$ & Extension service orientation & $0.679^{* *}$ \\
\hline $\mathbf{1 2}$ & Innovativeness & $0.340^{* *}$ \\
\hline $\mathbf{1 3}$ & Risk orientation & $0.374^{* *}$ \\
\hline $\mathbf{1 4}$ & Achievement motivation & $0.528^{* *}$ \\
\hline $\mathbf{1 5}$ & Business orientation & $0.051^{\mathrm{NS}}$ \\
\hline & & \\
\hline
\end{tabular}


The characteristics of input deals viz., education, training received, mass media usage, social participation, extension contact, scientific orientation, extension service orientation, innovativeness, risk orientation and achievement motivation had a positive significant relationship with their role in transfer of technology of agri-input dealers. Whereas age, experience as agri-input dealer, farming experience, land holding, mass media usage, social participation and business orientation had a non-significant relationship with their role in transfer of technology.

Findings of the study led to conclude that more than half of the agri-input dealers have perceived medium role, followed by high role and low role in transfer of technology. As agri-input dealers are linked with supply \& service of agri-inputs, there is more reliance on agri-input dealers by the farmers. So the farmers will approach them with easy access, high dependence, more credibility, clear intension and less ambiguity. Hence the role of agri-input dealers is very prominent in transfer of technology.

\section{References}

Sangameshganiger. 2012. Knowledge, perception and role Performance of input dealers in agro advisory services in Northern Zone of Karnataka. M.Sc. (Ag.) Thesis. Acharya NG Ranga Agricultural University, Hyderabad, India.

\section{How to cite this article:}

Kiran Kumar Reddy, U., P.V. Satya Gopal, V. Sailaja and Prasad, S.V. 2019. Role of AgriInput Dealers in Transfer of Technology. Int.J.Curr.Microbiol.App.Sci. 8(02): 2383-2388. doi: https://doi.org/10.20546/ijcmas.2019.802.277 